\title{
JENIS-JENIS BULLYING DAN PENANGANANNYA DI SD N MANGONHARJO KOTA SEMARANG
}

\author{
Lina Muntasiroh \\ Fakultas Ilmu Pendidikan, Universitas PGRI Semarang \\ Email: linamuntasiroh@gmail.com
}

\begin{abstract}
Bullying is not a new phenomenon in the world of Indonesian education. This is evidenced by the abundance of news about the acts of violence in print media and on television screens. Like the case that just happened in Brebes about students who pulled the chair of their female friends who were about to sit resulted in a fracture of the tailbone which was able to cause paralysis. This research to determine the types of bullying and its handling at SD N Mangunharjo, Semarang City. This research is a descriptive qualitative research that explains and describes the type of bulllying that occurs from class III-VI SD N Mangunharjo Semarang City which consists of victims and perpetrators of bullying. In addition there were also interviews with teachers and principals. The types of bullying that occurred included: Name of parents, funny names, and teasing. In addition students also carry out verbal bullying by commanding, cheering, and forcing. Physical bullying involves throwing a paper ball, pushing, pulling a headscarf, pinching, pulling a chair to be occupied, and hitting. Handling is carried out by giving direction every morning apples, ceremonies, reprimands and punishments that educate.
\end{abstract}

Keywords: Elementary School, Bullying, and Handling.

\begin{abstract}
Abstrak
Tindak bullying bukanlah fenomena baru didunia pendidikan Indonesia. Adanya kasus yang terjadi baru saja di Brebes tentang siswa yang menarik kursi teman perempuannya yang hendak duduk berakibat retak tulang ekor yang mampu menyebabkan kelumpuhan. Penelitian ini bertujuan untuk mengetahui jenis-jenis bullying dan penangannannya di SD N Mangunharjo Kota Semarang. Penelitian ini merupakan penelitian kualitatif deskriptif yang menjelaskan dan menggambarkan jenis bulllying yang terjadi dari kelas III-VI SD N Mangunharjo Kota Semarang yang terdiri dari korban dan pelaku bullying. Selain itu juga adanya wawancara dari guru serta kepala sekolah.Jenis-jenis bullying yang terjadi diantaranyabullying verbal dan fisik berupa : memanggil dengan nama orang tua, nama yang lucu,meledek, memerintah, dan menyoraki. Bullying secara fisik berupa melempar bola kertas, mendorong, menarik jilbab, mencubit, menarik kursi yang hendak diduduki, dan memukul. Penanganan yang dilakukan dengan memberikan arahan setiap apel pagi, upacara, teguran, dan hukuman yang mendidik.
\end{abstract}

Kata Kunci:Sekolah Dasar, Bullying, dan Penanganannya. 


\section{PENDAHULUAN}

Bullying merupakan kejadian di mana satu atau sekelompok siswa menekan siswa yang lain, biasa disebut dengan bullying. Menurut Tattum dalam Siswati (2009) bullying adalah "....the willful, conscious desire to hurt another and put him/her under stress". Olweus (1993) juga mengatakan hal yang serupa bahwa bullying adalah perilaku negatif yang mengakibatkan seseorang dalam keadaan tidak nyaman/terluka dan biasanya terjadi berulang-ulang "repeated during successive encounters".

Menurut Aris Merdeka Sirait dalam Moh Zainal (2016), kejadian bully di Sekolah Dasar seperti fenomena gunung es karena sedikit yang melaporkan. Berdasarkan catatan Komnas Perlindungan Anak Indonesia di tahun 2013, KPAI menerima 3.339 kasus pelanggaran terhadap anak dan $16 \%$ pelaku adalah anak usia kurang dari 14 tahun. Jumlah ini meningkat menjadi 4.965 kasus di tahun 2014, dimana pelaku bully meningkat menjadi $26 \%$. Hal ini menggambarkan bahwa lingkungan sekolah sudah tidak aman dari perilaku kekerasan.

Bullying yang terjadi di sekolah memiliki 3 karakteristik yang terintegrasi yaitu: 1) tindakan yang sengaja dilakukan pelaku untuk menyakiti korban, 2) tindakan yang dilakukan tidak seimbang sehingga menimbulkan rasa tertekan pada korban, dan 3) tindakan yang dilakukan secara berulangulang (Astuti, 2008).

Salah satu faktor yang mempengaruhi bullying adalah usia anak sekolah (6-12 tahun), dimana pada periode ini anak mulai diarahkan keluar dari kelompok keluarga dan mulai berinteraksi dengan lingkungan sosial yang akan berdampak pada hubungan interaksi dengan teman sebaya. Para peneliti dari Kings College, London, meneliti sekitar 7.771 anakanak, dan sekitar seperempat dari mereka (28 persen) ditindas atau di bully antara usia tujuh dan sebelas tahun, dan hal tersebut terbawa hingga di usia 50 tahun (Renny, 2014).

Di Jepang, school bullying dikenal dengan istilah 'ijime'. hal ini ditandai dengan gangguan berupa 
Jurnal Sinektik

Volume 2 Nomor 1, Edisi Juni 2019

Prodi PGSD Universitas Slamet Riyadi

ISSN 2620-6560 (print) ISSN 2620-746X (online)

ejekan, penindasan yang berakhir dengan tindakan bunuh diri dari sang korban. Kondisi 'ijime' dianggap serius dengan kisaran $2.5-3.5 \%$ dalam 1000 anak didik di Prefektur Aichi di mana merupakan lokasi dengan kasus ijime tertinggi, yaitu 3.500 kasus dan terendah di Gunma yaitu 500 kasus (Roychansyah, 2006). Kecenderungan ini tidak terlalu menonjol di Indonesia, kendatipun mungkin juga ada.

Secara psikologis bullying menimbulkan banyak akibat negatif seperti rendahnya harga diri hingga depresi dan pada jangka panjang bullying dapat menyebabkan trauma. Pihak sekolah masih sangat terbatas dalam menyikap dan menangani bullying. Sedangkan di pihak siswa masih belum banyak yang mengetahui tentang bullying beserta dampak yang ditimbulkan. Penelitian ini bertujuan untuk mengetahui perilaku bullying di SDN Mangunharjo Kota Semarang yang meliputi jenis-jenis bullying dan cara penanganannya.

\section{METODE PENELITIAN}

Penelitian ini menggunakan jenis penelitian kualitatif deskriptif utuk menggali secara mendalam serta memperoleh gambaran yang nyata tentang pemahaman dan penilaian dari perspektif pelaku, korban, guru, dan siswa mengenai perilaku bullying di SD N Mangunharjo Kota Semarang.

Penelitian deskriptif menurut Arikunto (2013: 3) adalah penelitian yang dimaksudkan untuk menyelidiki keadaan, kondisi, atau hal-hal lain yang sudah disebutkan, yang hasilnya dipaparkan dalam bentuk laporan penelitian.

Subjek penelitiannya adalah: 1 Kepala sekolah, 4 Guru,16Siswa kelas III-IV yang merupakan subjek utama berupa korban maupun pelaku perilaku bullying. Penelitian ini dilaksanakan pada bulan Januari 2019 di SD N Mangunharjo Kota Semarang.

Penelitian melalui tahap observasi awal untuk mengetahui keadaan lingkungan sekolah di SD N Mangunharjo Kota Semarang. Dilanjutkan dengan wawancara yang dilakukan pada subjek yang diteliti melalui catatan tertulis atau melalui perekaman video/audio tapes, dan pengambilan foto. 
Pada saat pengambilan data, dan disajikan, yang pada tahap peneliti didampingi oleh guru masing- akhirnya dapat ditarik kesimpulan.

masing kelas. Teknik analisis data melakukan penelitian ini adalah menggunakan uraian kata-kata yang menjelaskan jenis-jenis dan penanganan bullying di SD $\mathrm{N}$ Mangunharjo Kota Semarang yang diambil dari hasil observasi dan wawancara. Kemudian data tersebut dapat disajikan berupa laporan yang dapat didata, direduksi, atau dikoreksi

\section{HASIL DAN PEMBAHASAN}

Dari jawaban-jawaban yang diberikan oleh subjek pada saat peneliti melakukan wawancara dan melihat hasil observasi tampak bahwa fenomena bullying juga marak terjadi di kalangan siswa-siswa Sekolah Dasar Negeri Mangunharjo Kota Semarang. Berikut ini adalah hasil temuan di lapangan.

Tabel 1. Bentuk-bentuk bullying di SD N Mangunharjo

\begin{tabular}{lcc}
\hline \multirow{2}{*}{ Bentuk bullying } & \multicolumn{2}{c}{ Waktu terjadi } \\
\cline { 2 - 3 } & $\begin{array}{c}\text { Jam } \\
\text { pelajaran }\end{array}$ & Istirahat \\
\hline Diejek & $\checkmark$ & $\checkmark$ \\
\hline $\begin{array}{l}\text { Dipanggil nama } \\
\text { tua }\end{array}$ & orang & $\checkmark$ \\
\hline Disoraki & $\checkmark$ & $\checkmark$ \\
\hline Ditertawai & $\checkmark$ & $\checkmark$ \\
\hline Dipukul & $\checkmark$ & $\checkmark$ \\
\hline Dicubit & & $\checkmark$ \\
\hline Dijegal & $\checkmark$ & $\checkmark$ \\
\hline Ditarik hijab & $\checkmark$ & $\checkmark$ \\
\hline Dijambak rambut & $\checkmark$ & \\
\hline Dilempar bola kertas & & $\checkmark$ \\
\hline Dibahasi kursi & & $\checkmark$ \\
\hline Ditarik kursi \\
hendak duduk
\end{tabular}


Rata-rata bullying dilakukan secara berulang artinya bukan hanya dilakukan sekali dan dilakukan dengan orang yang sama. Beberapa pelaku bullying menyebutkan bahwa bullying dilakukan sebatas untuk bermain dan untuk membalas dendam sekalipun mereka menyadari tindakan yang dilakukan tidak baik. Namun, kesadaran tentang baik dan tidak baik saja ternyata tidak cukup bagi pelaku untuk tidak kembali melakukan hal yang sama.

Pengaruh media informasi televisi memiliki efek negatif pada anak seperti mengajari anak menjadi stereotip, mencontohkan model agresi kekerasan, dan menyajikan pandangan yang tidak realistis tentang dunia (Dubow, Huesmann, Greenwood, dan Murray (2007 dalam Santrock, 2011). Anak laki-laki yang sering menonton tayangan kekerasan di televisi besar kemugkinan untuk melakukan tindak pidana kekerasan, mengejek orang lain, mengancam menggunakan kekerasan terhadap anak-anak lain, memecahkan jendela, dan menuliskan slogan di dinding (Santrock, 2011).

Anak kelas VI dengan inisial S yang memiliki badan sedang dan tidak pernah bisa diam dan selalu ramai ketika di kelas. Sedangkan menurut TA tindakan bullying dilakukan untuk seru-seruan dan menunjukkan kepada yang lain jika TA memiliki kuasa yang lebih dibanding dengan yang lain. Bullyingyang dilakukan TA terus berulang meski sudah ada teguran dari guru. TA biasa mengejek, melempar bola kertas dan memanggil teman dengan nama orang tua.

Selain dilakukan oleh laki-laki bullying juga dilakukan oleh perempuan, sebut saja GB. Siswa ini beberapa kali melakukan bullying kepada teman sekelasnya. Selain memanggil dengan nama orang tua GB juga beberapa kali melempar bola kertas kepada teman yang lain, alasan melakukan itu cukup sederhana untuk tertawa bersama dengan teman-teman atau sebagai hiburan. Namun, kegiatan bullying yang dilakukan GB tidak berlarut-larut. GB tidak mengulangi tindakan bullying setelah mendapat teguran dari guru.

Kelas V yang termasuk kategori kelas tinggi juga melakukan tindakan bullying. Alasan tindakan bullying yang dilakukan tidak jauh beda dengan kelas VI. DHH mengaku 


\section{Jurnal Sinektik}

Volume 2 Nomor 1, Edisi Juni 2019

Prodi PGSD Universitas Slamet Riyadi

ISSN 2620-6560 (print) ISSN 2620-746X (online)

tindakan bullying yang dilakukan atas

dasar lucu dan agar senang. DHH

mengaku pernah menarik kursi teman

ketika hendak duduk, memanggil

dengan julukan lain atau nama orang

tua, dan beberapa hal lain yang biasa

dilakukan ketika jam istirahat. Karena

pernah ditegur guru DHH tidak melakukan kegiatan ini secara berulang.

Sama dengan I dan FSN mereka berdua ini juga melakukan bullyingdengan alasan untuk seruseruan, pengawal permainan. Tindakan selain bullying verbal berupa memanggil dengan julukan dan nama orang tua. I dan FSN juga pernah menarik kursi teman ketika hendak duduk dan melempar teman dengan bola kertas yang merupakan bullying secara fisik.

F kelas III juga melakukan bullying dengan sesama teman lakilaki. F mengaku tindakan bullying yang dilakukan untuk hiburan, sekalipun jarang melakukan $\mathrm{F}$ belum pernah dimarai guru. $\mathrm{F}$ beberapa kali memangil teman dengan julukan yang lucu, menarik kursi teman yang hendak duduk, dan melempar bola kertas ke teman.
KA yang merupakan korban bullying selain dipanggil dengan nama orang tua, ditarik kursi ketika hendak duduk juga beberapa kali dicubit. Merasa down juga dirasakan oleh KA. SKN kelas V juga menjadi korban bullying yang mengaku pernah dipanggil dengan nama julukan orang tua. SKN sering merasa kesal, pasalnya bukan hanya dipanggil dengan nama julukan SKN juga sering ditarik kursi ketika hendak duduk, diejek, dan dijahili.

Berbeda dengan MR yang bukan hanya diperlakukan seperti itu, MR sering dipukul dan dijegal oleh pelaku bullying. Untuk kelas IV MF mengaku pernah dipanggil dengan julukan selain namanya, ditarik kursi ketika hendak duduk, dan ditarik hijabnya. MF merasa bosan diperlakukan seperti itu namun dia sendiri belum pernah melaporkan tindakan itu ke orang tua ataupun guru.

Tindakan yang sama juga dirasakan oleh temannya yaitu JA, yang mengaku juga pernah dipanggil dengan julukan selain namanya, ditarik kursi ketika hendak duduk, dan duduk. JA mengaku sempat down dan menjadi pendiam. Selain itu JA 
Jurnal Sinektik

Volume 2 Nomor 1, Edisi Juni 2019

Prodi PGSD Universitas Slamet Riyadi

ISSN 2620-6560 (print) ISSN 2620-746X (online)

juga marah ketika diperlakukan demikian, namun tetap saja tidak ada perlawanan ataupun melaporkan dengan guru karena menganggap hal tersebut sudah biasa.

Kelas III dengan inisial DAJ mengaku pernah dipanggil dengan julukan selain namanya, sering ditarik kursi ketika hendak duduk, bahkan dijambak rambutnya. DAJ kerap merasa kesal diperlakukan demikian, tapi dia takut untuk melaporkan hal yang sudah dialami kepada guru maupun orang tua. Beberapa kali DAJ hanya mencoba menasehati. ARA merupakan teman DAJ yang juga beberapa kali menjadi korban tindakan bullying. ARA mengaku beberapa kali dipanggil dengan nama orang tua, ditarik kursi ketika duduk, dan dipukul dadanya. ARA memilih diam atau menasehati dibanding melaporkan tindakan itu ke guru karena menganggap perlakuan itu sudah biasa diterimanya.

Jenis bullying yang dilakukan berdasarkan hasil wawancara adalah bullying fisik dan verbal. Kedua jenis bullying ini dilakukan untuk memberikan rasa senang, balas dendam, dan sebagai permainan. Namun, tidak jarang hal tersebut menyakiti korban bullying yang ratarata memilih diam dibanding harus melawan. Korban bullying lebih merasa takut karena menyadari sekalipun melawan akan terjadi perlawanan kembali dari pelaku bullying yang menjadikannya hanya memendam rasa benci tersebut sendiri. Namun, ada beberapa korban bullying yang memberanikan diri untuk melapor kepada guru maupun orang tua sebagai perlawanan dan untuk melakukan pencegahan agar tidak terjadi pengulangan perilaku tersebut.

\section{Penanganan dan pencegahan bullying di SD N Mangunharjo}

Baru-baru ini ada sebuah kasus yang kembali menyakiti dunia pendidikan, kisah yang dialami oleh anak SMA di Brebes. Adanya bercandaan yang dilakukan sesama teman berawal dari menarik kursi ketika hendak duduk yang mengakibatkan cedera tulang ekor parah. Spontan setelah kejadian siswa ini duduk kelantai dan kesakitan hingga tidak sadar. Dampaknya mulai dari kelumpuhan sampai kematian. Kisah ini disampaikan sebagai bentuk keprihatinan oleh ayah korban Ibnu 
Yahya pada Selasa 2 Februari 2019 di akun facebook pribadinya. Dari bercandaan yang terlihat lucu, tapi bahaya yang mengintai begitu mengerikan. Masih banyak kejadiankejadian lain yang belum terpubikasikan, sehingga perlu adanya refleksi bersama antar semua elemen baik pendidikan maupun masyarakat agar tidak terus menerus terulang dan sebagai tamparan bersama.

Hasil data yang diperoleh dari wawancara menyebutkan beberapa cara yang dilakukan guru dalam menangani kasus bullying yang terjadi di SD N Mangunharjo Kota Semarang yaitu: melalui penyampaian beberapa arahan ketika upacara, pembiasaan senam hari jum'at, melalui implementasi kurikulum 2013 dengan pendidikan penguatan karakternya, adanya peringatan hingga teguran keras ketika melakukan tindakan bullying dengan ancaman pengurangan nilai telah dilakukan oleh guru. Namun, dalam kenyataannya pengulangan bullying sering sekali terjadi pada pelaku dan korban yang sama.

Menurut Soejatmiko (2013) Bullying di sekolah paling sering terjadi di lapangan bermain. Temuan tersebut berbeda dengan penelitian kami maupun penelitian di Jepang yang mendapati ruang kelas sebagai lokasi tersering terjadinya bullying. Interaksi antar-murid paling banyak terjadi di lapangan bermain dan kelas, sehingga bullying paling sering dialami korban di kedua lokasi tersebut. Bullying dapat terjadi dimana saja, terutama di lokasi yang minim pengawasan oleh orang dewasa.

Hal-hal ini dilakukan ke siswa lain yang lebih lemah yang notabennya teman sekelas dari pelaku bullying. Terjadinya bullying itu sendiri adalah ketidakhadiran guru di dalam kelas, cara berfikir korban yang sedikit lamban, fisik korban yang lemah, kurangnya kemampuan korban dalam bersosialisasi, minder, perbedaan postur tubuh antara pelaku dan korban, dan kebiasaan pelaku berbiacara kasar di rumah. Ketika bullying berlangsung rata-rata korban hanya diam dan tidak mau menegur pelaku, sehingga pelaku merasa senang dan terus-menerus melakukan bullying tersebut. Tidak ada pembelaan dari korban yang menjadikan perilaku bullying itu terus terjadi. 
Dalam sebuah jurnal psikologi UNDIP (Siswanti, 2009) yang membahas tentang fenomena bullying yang terjadi di SD Semarang menjelaskan beberapa hal yang sebenarnya bisa dilakukan oleh guru agar bullying di lingkungan sekolah tidak terus berkembang, yaitu: Menetapkan aturan-aturan yang jelas mengenai bullying di ruang kelas dan di lingkungan sekolah secara menyeluruh, melatih seorang dewasa agar peka terhadap fenomena tersebut, menyediakan pengawasan yang dilakukan oleh orang dewasa secara memadai khususnya dalam wilayah-wilayah yang kurang terpantau memungkinkan terjadinya bullying.

Menurut Trinita Anjasuma (2018) mengatakan bahwa bullying akan dapat dikurangi secara signifikan apabila sistem tempat dimana bullying tersebut muncul tidak diberikan imbalan apapun, dan justru memberikan denda atau hukuman tiap kali perilaku bulying muncul, salah satu program yang sangat komperhensif yang ditujukan untuk menanggulangi bullying Dan terbukti efektif yakni the bully busters program.
Menurut Novan Ardy Wiyani (2014) bullying mampu ditangani dengan menumbuhkan suasana aman dan nyaman secara psikologis yang terlihat dari halhal berikut: tidak adanya rasa waswas pada siswa, hubungan yang penuh kekeluargaan, tidak ada pemalakan atau pemerasan, barang-barang aman dari pencurian, siswa diterima dan dihargai keberadaannya, memiliki kebebasan, serta bebas dari imtimidasi.

Bullying mampu diredam dengan melakukan 8 kemampuan verbal: Setuju dengan apa yang dikatakan pelaku, Lemahkan pelaku dengan humor, Jadikan pelaku bosan dengan pertanyaan-pertanyaan, Jadikan pelaku bosan dengan jawaban-jawaban yang sama, Menjawab dengan tenang dan percaya diri, Melalui komunikasi asertif, Ubah situasi negatif menjadi positif, Beri ijin pelaku mengejek (Sejiwa, 2008).

Model pencegahan lain misalnya ditawarkan oleh Rigby dalam (Husmiati Yusuf, 2005) yang menyarankan sepuluh garis panduan bagi sekolah untuk menangani masalah perilaku buli di sekolah. 
Garis panduan tersebut antara lain:

Mulai dengan pendefinisian perilaku buli yang jelas dan dapat diterima, mengakui bahwa perilaku buli berlaku dalam berbagai bentuk, mengenali apa yang berlaku di sekolah, menyusun rencana tindakan, menyediakan kebijakan anti bullying, menyediakan media bagi murid atau kelompok murid tentang apa yang akan dilakukan bagi membantu mereka, mendorong tingkah laku yang dapat mendatangkan pengaruh positif terhadap tingkah laku interpersonal murid, mengatasi setiap kejadian bullying secara bijaksana, menyediakan bantuan kepada murid yang menjadi korban buli, bekerja secara konstruktif dengan pihak lain terutama orang tua atau komite sekolah.

\section{SIMPULAN}

Beradasarkan hasil yang telah diajabarkan sebelumnya mengenai identifikasi perilaku bullying di Sekolah Dasar Negeri Mangunharjo dapat disimpulkan sebagai berikut:

1. Jenis bullying dibagi menjadi dua, kekerasan fisik dan verbal. Kekerasan fisik berupa, mencubit, memukul, mendorong, menarik jilbab, menarik kursi ketika hendak duduk, dan menjegal. Kekerasan verbal yaitu : memanggil dengan sebutan orang tua, mengejek, dan memarahi.

2. Upaya yang dilakukan Guru SD N Mangunharjo Kota Semarang adalah dengan memberikan nasehat kepada siswa. Memberikan pemantauan ketika jam istirahat, mengadakan apel pagi setiap hari jumat dan senam bersama, dan memberikan motivasi dan semangat kepada siswa yang sering terkena bullying. Guru juga menerapkan sikap toleransi dan saling menghargai sesama teman dengan sistem kurikulum 2013 yang membantu siswa dalam pengembangan kepribadian siswa.

Berdasarkan kesimpulan yang telah disusun, peneliti mencoba memberikan saran untuk mencegah bullying, yaitu:

a. Guru menambah wawasan perihal bullying dari buku, artikel, jurnal, atau surat kabar, dan internet agar memahami secara utuh bullying dan penanganannya.

b. guru diharapkan mengenali karakteristik pelaku dan korban bullying agar dapat mencegah dan 


\section{Jurnal Sinektik}

Volume 2 Nomor 1, Edisi Juni 2019

Prodi PGSD Universitas Slamet Riyadi

ISSN 2620-6560 (print) ISSN 2620-746X (online)

mengatasi apabila terjadi bullying

yang muncul sewaktu-waktu.

c. Mengadakan konseling atau pemahaman bersama tentang bullying pada siswa ketika apel pagi atau upacara bendera.

d. Perlu adanya guru piket yang dapat mengawasi perilaku siswa ketika jam istirahat.

e. Adanya tindak lanjut yang tegas ketika mengetahui adanya tandatanda perilaku bullying dari pelaku bullying.

f. Mengajak orang tua siswa turut andil dalam memberi pemahaman kepada anak nya agar terhindar dari perilaku bullying.

\section{DAFTAR PUSTAKA}

Anjasuma, Trinita.2018. Analisis Sebab-Akibat Perilaku Bullying Remaja. (Skripsi). Yogyakarta:Fakultas

Keguruan dan Ilmu Pendidikan Universitas Sanata Dharma Yogyakarta.

Astuti, Ponny Retno. 2008. Meredam bullying: 3 Cara Efektif Mengatasi K.P.A. Jakarta: Grasindo.

Moh Zainal Rohman. 2016. Hubungan antara usia tingkat kelas dan jenis kelamin dengan kecenderungan menjadi korban bullying. The 3rd
Universty Research

Colloquium, ISSN 24079189

Novan Ardy Wiyani. 2014. Save our children from school bullying. Yogyakarta: ARRUZZ Media.

Renny Sundayani. 2014. Anak Korban Bullying Berpotensi Bunuh Diri di Usia 50. Di akses pada 05 November 2014, dari:http://okezone.com/okez one.lifestyle. htm Roychansyah, Muhammad Sani. 2006. Sedikit Mengupas 'Ijime'.

Santrok, J. W. 2011. Perkembangan anak, jilid 1, edisi 11. Jakarta: Erlangga.

Siswanti, Contrie Ganes Widayanti. 2009. Fenomena bullying di Sekolah Dasar Negeri Semarang. Jurnal Psikologi UNDIP. Vol.5 No.2 Desember Fakultas Psikologi Universitas Diponegoro Semarang

Sejiwa. (2008). Bullying!. Jakarta: PT Grasinndo.

Soejatmiko, Nur Hamzah, dan Anastasia. 2013. Gambaran Bullying dan Hubungannya dengan Masalah Emosi dan Perilaku pada Anak Sekolah Dasar. Sari Pediatri, Vol. 15, No. 3. 
Jurnal Sinektik

Volume 2 Nomor 1 , Edisi Juni 2019

Prodi PGSD Universitas Slamet Riyadi

ISSN 2620-6560 (print) ISSN 2620-746X (online) 